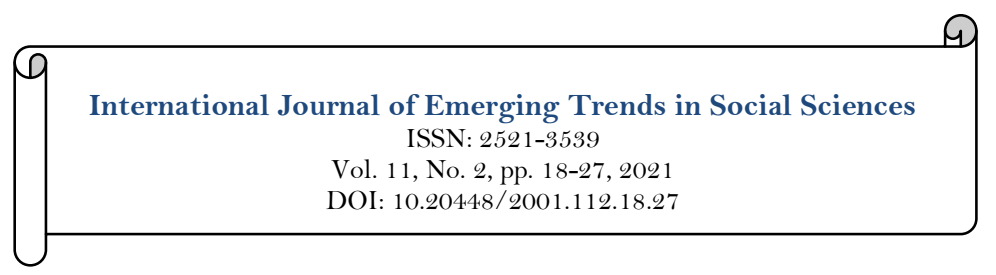

\title{
What Really Matters: The Effect of Covid-19 on the Factors of Life Satisfaction
}

\author{
Julius Janacek \\ University of J. E. Purkyne in Usti nad Labem, Faculty of Social and Economic Sciences, Czech Republic. \\ Email:juliusjanacek@post.cz
}

\begin{tabular}{|c|c|}
\hline Abstract & \\
\hline $\begin{array}{l}\text { This article investigates the effect of the Covid-19 pandemic on the } \\
\text { structure of factors of life satisfaction in the city of Usti nad Labem, } \\
\text { Czech Republic. The dataset is based on a questionnaire survey } \\
\text { conducted in Usti nad Labem, Czech Republic. Subsequent data analysis } \\
\text { is conducted using ordinal logistic regression models. The results show } \\
\text { that the emergence of the pandemic had a significant impact on life } \\
\text { satisfaction factors. Firstly, the importance of family came to the fore: } \\
\text { being in a relationship or being married proved to be a significant factor } \\
\text { of life satisfaction during the pandemic but not before the pandemic. } \\
\text { Secondly, a negative association between drinking alcohol and life } \\
\text { satisfaction emerged during the pandemic. Alcohol probably started to } \\
\text { be the tool for stress relief. Thirdly, sport became a significant positive } \\
\text { factor of women's life satisfaction. Sport most likely became an effective } \\
\text { way of keeping oneself in balance. Results indicate that during a difficult } \\
\text { time period there are different ways of how to deal with it. In this way } \\
\text { doing sports and drinking alcohol seem to be substitute activities. }\end{array}$ & $\begin{array}{l}\text { Keywords: } \\
\text { Covid } \\
\text { Covid-19 } \\
\text { Happiness } \\
\text { Life satisfaction } \\
\text { Factors. } \\
\text { JEL Classification } \\
\text { D01, D60, I31. } \\
\text { Licensed: } \\
\text { This work is licensed under a } \\
\text { Creative Commons Attribution } 4.0 \\
\text { License. } \\
\text { Publisher: } \\
\text { Scientific Publishing Institute } \\
\text { Received: } 2 \text { November } 2021 \\
\text { Revised: } 7 \text { December } 2021 \\
\text { Accepted: } 20 \text { December } 2021 \\
\text { Published: } 28 \text { December } 2021\end{array}$ \\
\hline
\end{tabular}

Funding: This article was created with the support of the Smart project (grant number: CZ.02.1.01/0.0/0.0/17_048/0007435), University of Jan Evangelista Purkyne, Usti nad Labem, Czech Republic. Competing Interests: The author declares that there are no conflicts of interests regarding the publication of this paper.

\section{Introduction}

The global Covid-19 pandemic of 2020 had undoubtedly impact on many areas of human lives all around the planet. Economic structures and relations changed (Mulligan, 202 1; Pak et al., 2020) as the world's safety situation changed in many areas (Bitler, Hoynes, \& Schanzenbach, 2020) tourism worldwide was reduced to quite low figures (Qiu, Park, Li, \& Song, 2020) etc. In this article, the question is asked whether this situation also affected the structure of factors which are important for people's happiness. Happiness ${ }^{1}$ is the product of all of our experiences and thus is connected with all areas of our lives starting with family and ending with one's own financial situation. Causing great changes in our day-to-day experience, the Covid-19 pandemic should then also affect how happy people feel. Not only can we expect the general level of life satisfaction the be different but it is also possible that the factors which were important during normal times before that pandemic might not be important during the pandemic and vice versa. Such a discovery could show factors which have become important for people when difficult times arise. Since peoples' notions about what makes them happy often differ from what is really important (Diener, Gohm, Suh, \& Oishi, 2000) such investigation

${ }^{1}$ Although the terms happiness and life satisfaction might have a different meaning for many people and they are strictly separated in many scientific disciplines, in this paper, the practice of economics of happiness is followed and these terms are used interchangeably. A more detailed explanation on this matter is given e.g. by Frey (2008). 
could prove useful for people during difficult time periods: they could re-prioritize their goals and thus reach higher levels of life satisfaction with resources kept constant.

The main hypotheses of this research are:

1) In the sample, peoples' factors of life satisfaction changed with the coming of the Covid-19 pandemic.

2) Different factors of life satisfaction started/ceased to be important for men and different for women.

3) Besides these hypotheses, specific hypotheses concerning individual factors studied in the questionnaire could also be listed. For example, one hypothesis could be: the factor health became important during the pandemic for men. For practical purposes, all of these hypotheses are not stated here.

\section{Literature Review}

Since its emergence, economic science has worked with the term utility as something that is wanted by people and no in-depth investigation of this concept was needed. Then, in the 1970s the so-called "economics of happiness" came to the forefront by connecting the terms utility and happiness - happiness was taken to equal utility.

The new scientific area of the economics of happiness started to investigate different social and economic factors (see, e.g., Lambert et al. (2014)) making new contributions to the study of human behavior. Many economists even called this shift revolutionary (see, e.g., Frey (2008)). This would correspond to the fact that three Nobel prizes were awarded for contributions in the area of economics of happiness (for example Angus Deaton). This study investigates whether the changes in social and health conditions in one country (namely the spread of Covid-19) can bring about a change in factors and predictors of happiness.

Significant changes in society and one's own environment affects the life of individuals in many areas: an economic crisis has large impact on peoples' well-being (D’Agostino, Gagliardi, Giusti, \& Potsi, 2019; Gonza \& Burger, 2017) and also for example on the role of finances (Sarracino \& Piekałkiewicz, 2021). Similarly, armed conflicts or wars affect peoples' long-term well-being (Teerawichitchainan \& Korinek, 2012) and psychological state (Hassan, Ventevogel, Jefee-Bahloul, Barkil-Oteo, \& Kirmayer, 2016). Also, one's well-being is affected by adverse social shifts (Ren \& Treiman, 2016). It naturally follows that an outbreak of an infectious diseases changes peoples' lives in many areas as well (De Souza et al., 2018; Yadav \& Rawal, 2015).

The spread of the Covid-19 virus has had quite an impact on many aspects of human lives. On the macroeconomic level it has influenced economic activity (Fezzi \& Fanghella, 2020) financial markets (Ashraf, 2020) and international travel (Iacus, Natale, Santamaria, Spyratos, \& Vespe, 2020). On the microeconomic level either by fear of the disease or by the means of social restrictions it has affected peoples' family lives (Patrick et al., 2020) mental health (Wanberg, Csillag, Douglass, Zhou, \& Pollard, 2020) and physical health (Garfin, Silver, \& Holman, 2020).

The pandemic has had direct effect on peoples' subjective well-being (Kivi, Hansson, \& Bjälkebring, 2021; Zacher \& Rudolph, 2021). It seems quite natural that both the disease itself and all adopted regulatory measures have had a strong influence on how people feel. However, it is still unclear whether the coming of the pandemic has affected the importance of concrete factors of life satisfaction. Janáček and Rybáček (2020) have shown that factors of life satisfaction differ significantly across countries. Thus, it is possible that they also differ when we take into account one country across different time periods. The aim of this study is to investigate whether the Covid-19 pandemic situation has changed factors which are connected with peoples' happiness. In this study, this is done with an example of the medium-sized Czech industrial city of Ustí nad Labem. It is possible that during crisis different life aspects become important for the well-being of people. The outcome of this study may show behavioral patterns which can apply not only in the case of a global pandemic but also in the case of any difficult time periods in general.

\section{Methodology}

In this section, the methodological approach which was used in this study is described. First (section 3.1: Data), details about how the data was collected is described. After this (section 3.2: Models), the statistical methods used to investigate the matter of this research is described.

\subsection{Data}

The analysis is based on two questionnaire surveys conducted in October of $2019(\mathrm{n}=701,327$ men) and October of 2020 ( $\mathrm{n}=517,218 \mathrm{men}$ ) in the city of Usti nad Labem, Czech Republic. In both cases, the surveys were conducted in October to ensure mutual comparability. Also, the places where the questionnaires were distributed were the same in both years; these were five public areas in five different parts of the city. The passers-by were addressed at random. The participation rate in the survey was around $60 \%$. Our methodology and research was approved by ethics committee of our university.

While in October of 2019 more than likely nobody in the city knew what Covid-19 was and the lives of the people went on as usual, while in October 2020 the Covid-19 crisis was in full swing. The second wave of the pandemic had started and most likely every person's life was directly influenced by this shift. The effect was economic (e.g., many businesses were forced to close down), social (e.g., lives of many families changed when the children were not allowed to attend schools), health-wise (many people became infected by the 
Covid-19 virus) and psychological (many people both infected and those who were not infected were often afraid of their own or other peoples' health). Therefore, a comparison between these two moments of time offers an opportunity to directly study the effect of the pandemic. Although other aspects of peoples' lives could change independently of the Covid-19 crisis, during this time period the Covid-19 change was certainly the most significant one giving the results the desired value. The sample of this study is not representative of the population of the city, which puts a limit to generalization of the findings. However, it can be expected that the results apply to a large part of the population of the city.

The questionnaire included 17 questions related to different areas of peoples' lives. Many questions regarding many different areas were intentionally included so that the research could take into account the significance of various socio-economic factors. The variables based on these questions are listed in Table 1.

Table-1. List of variables based on questions answered by the respondent, their description and scales.

\begin{tabular}{|c|c|c|}
\hline Variable & Description & Scale \\
\hline $\begin{array}{l}\text { Life } \\
\text { Satisfaction }\end{array}$ & $\begin{array}{l}\text { Satisfaction with the quality of their current life } \\
\text { (question: "how satisfied are you with the quality of } \\
\text { your life on a scale of } 0-10 \text { where } 0 \text { is the worst quality } \\
\text { and } 10 \text { is the best quality?") }\end{array}$ & $\begin{array}{l}0-10: 0-\text { least satisfied, } 1- \\
\text { most satisfied }\end{array}$ \\
\hline $\begin{array}{l}\text { Health } \\
\text { Physical }\end{array}$ & $\begin{array}{l}\text { Self-reported physical health (question: "how would you } \\
\text { assess your physical health on a scale of } 0-10 \text { where } 0 \text { is } \\
\text { the worst health and } 10 \text { is the best health?") }\end{array}$ & $0-10: 0-$ worst, $1-$ best \\
\hline $\begin{array}{l}\text { Health } \\
\text { Mental }\end{array}$ & $\begin{array}{l}\text { Self-reported mental health (question: "how would you } \\
\text { assess your mental health on a scale of 0-10 where } 0 \text { is } \\
\text { the worst health and } 10 \text { is the best health?") }\end{array}$ & $0-10: 0-$ worst, 1 - best \\
\hline $\begin{array}{l}\text { Commuting } \\
\text { Time }\end{array}$ & $\begin{array}{l}\text { Duration of the daily commute to school, work or } \\
\text { elsewhere in minutes (the way there and back) }\end{array}$ & Integer \\
\hline Cigarettes & Number of cigarettes smoked per day & Integer \\
\hline Alcohol & $\begin{array}{l}\text { Alcohol units consumed per week ( } 1 \text { alcohol unit } \\
\text { represents } 0.5 \text { liter of beer or } 2 \mathrm{dcl} \text { of wine or one "shot" } \\
\text { of some stronger type of alcohol) }\end{array}$ & Integer \\
\hline Sport Time & Number of hours spent doing sport activities per week & Integer \\
\hline TV Time & Number of hours spent watching TV per week & Integer \\
\hline Friends Time & Number of hours spent with friends per week & Integer \\
\hline Salary & Monthly salary in CZK & Integer \\
\hline Transfers & Monthly transfers received in CZK & Integer \\
\hline $\begin{array}{l}\text { Marital } \\
\text { Status }\end{array}$ & Current marital status - categorical variable & $\begin{array}{l}\text { O - Single without a partner, } \\
1 \text { - Unmarried with a partner, } \\
2 \text { - Married }\end{array}$ \\
\hline Education & Education achieved - categorical variable & $\begin{array}{l}\text { O - Elementary, } 1-\text { High } \\
\text { school without state exam, } 2 \\
- \text { High School with state } \\
\text { exam, } 3-\text { University } \\
\text { Bachelor, 4- University } \\
\text { Masters }\end{array}$ \\
\hline Work Status & Current work status - categorical variable & $\begin{array}{l}\text { o - Student, } 1 \text { - Employed, } 2 \\
\text { - Unemployed, } 3 \text { - Retired }\end{array}$ \\
\hline Children & Number of children & Integer \\
\hline $\begin{array}{l}\text { Gender } \\
\text { Female }\end{array}$ & Gender of the respondent & $0-$ man, $1-$ woman \\
\hline Age & Age of the respondent & Integer \\
\hline
\end{tabular}

The level of happiness was obtained using the same method that is used in the annual World Happiness Report (see, e.g., Helliwell, Layard, and Sachs (2019)) published by the United Nations, that is by asking the respondents "How satisfied are you with the current quality of your life?" The scale was set from 0 to 10 with $\mathrm{o}$ being the least satisfied and 10 being the most satisfied.

As for physical health and mental health, I am aware of the fact that these variables mirror only what people have reported about themselves (reported health). This can be different from their real health state. To evaluate one's health state as such a much more detailed medical analysis would be needed. However, this type of measurement would not be possible to conduct in the streets where the data was gathered. Nevertheless, since self-rated health status has been accepted as a valid predictor of physical well-being and mortality (Kulkarni, 2015) and is used in medicine on a regular basis (Benyamini, Idler, Leventhal, \& Leventhal, 2000) it gives a good approximation of the real health state. Based on this fact, when the results of this analysis are interpreted, the reported values are referred to straightforwardly as physical health and mental health. 
In this study, salary and transfers are differentiated between. Salary is the amount of money earned. On the other hand, the variable Transfers refers to the amount of money received from other sources than work: rent received for an apartment, social support, pension, etc. I made this distinction to test whether money received for work has different significance for happiness than money received without any work done.

Both variables Salary and Transfers were measured in Czech crowns (CZK). The exchange rates between the Czech crown and Euro according to the European Central Bank during the times of the survey were: on October $18^{\text {th }} 2019$ when $1 \mathrm{CZK}=0.03900 \mathrm{EUR}$ and on October $10^{\text {th }} 2020,1 \mathrm{CZK}=0.03797 \mathrm{EUR}$.

As for the variable Marital Status, there were three possible answers: single without a partner, not married with a partner and married. In some surveys, the respondent is also offered the options divorced or widowed. However, in this study I omitted these categories. In both cases the person was put into the category single without a partner (if they did not have any partner). I did not want to investigate the significance of these two additional categories as I was only interested in the significance of the person's partner relations at the moment of the survey (if they have a partner or not and if they are married or not.

\subsection{Models}

Statistical analysis of the data was performed using logistic regression models. Four separate models were constructed: for men during the year 2019, for women during 2019, for men during 2020 and for women during the year 2020. In all cases, the dependent variable was Life Satisfaction and the independent variables were based on all questions from Table 1.

Most variables were included in a linear form but the financial aspects are used in logarithmic transformation as it has been shown that their effect on happiness declines with the total level of finances (Kahneman \& Deaton, 2010). Further, for variables Marital Status, Education and Work Status corresponding dummy variables were created. In each case, the reference level was the first category shown in Table 1 . The variable Children Yes as a dummy variable was also included showing whether the respondent had a child/children or not.

This study is based on static data at two different time points. Therefore, it is crucial to note that relations found by the regression models do not show causality directions. They show relations only. For each significant factor, it is therefore necessary to consider both causality directions as well as the possibility of a third unobserved factor mediating the relation between the observed factors. In order to determine the causality direction, more detailed research would be needed.

\section{Results and Discussion}

\subsection{Descriptive Statistics}

Table 2 presents the summary of statistics for the tested sample. As with the subsequent regression models here too, the sample was divided into for sub-groups: men and women, year 2019 and year 2020.

Table-2. Summary of statistics.

\begin{tabular}{|c|c|c|c|c|c|c|c|c|}
\hline & \multicolumn{4}{|c|}{ Men } & \multicolumn{4}{|c|}{ Women } \\
\hline & \multicolumn{2}{|c|}{2019} & \multicolumn{2}{|c|}{2020} & \multicolumn{2}{|c|}{2019} & \multicolumn{2}{|c|}{2020} \\
\hline Variable & Mean & Std. Dev. & Mean & Std. Dev. & Mean & Std. Dev. & Mean & Std. Dev. \\
\hline Life Satisfaction & 7.38 & 1.96 & 7.56 & 1.87 & 7.41 & 1.93 & 7.72 & 1.76 \\
\hline Physical Health & 7.28 & 1.96 & 7.22 & 2.16 & 7.06 & 2.05 & 7.35 & 1.9 \\
\hline Mental Health & 7.59 & 2.07 & 7.82 & 2.07 & 7.36 & 2.32 & 7.63 & 2.06 \\
\hline Commuting Time & 44.53 & 41.23 & 45.12 & 47.46 & 39.26 & 40.67 & 35.48 & 35.28 \\
\hline Cigarettes & 4.07 & 6.56 & 4.72 & 7.58 & 2.81 & 5.38 & 3.48 & 6.19 \\
\hline Alcohol & 4.4 & 6.82 & 6.09 & 9 & 2.31 & 3.86 & 3.15 & 6.05 \\
\hline Sport & 4.7 & 5.65 & 3.95 & 4.35 & 3.07 & 3.7 & 4 & 5.83 \\
\hline $\mathrm{TV}$ & 11.51 & 13.36 & 9.09 & 11.44 & 11.35 & 10.69 & 11.68 & 12.8 \\
\hline Friends & 12.77 & 10.9 & 13.76 & 14.59 & 11.69 & 10.91 & 13.15 & 12.71 \\
\hline Children & 1 & 1.18 & 0.96 & 1.28 & 1.1 & 1.25 & 1.1 & 1.17 \\
\hline Children Yes & 0.51 & 0.5 & 0.46 & 0.5 & 0.55 & 0.5 & 0.57 & 0.5 \\
\hline Salary & 15006 & 13632 & 16179 & 15164 & 10799 & 11451 & 9550 & 11139 \\
\hline Transfers & 3236 & 5033 & 3759 & 6149 & 3961 & 5615 & 5516 & 6424 \\
\hline Age & 35.95 & 16.56 & 34.84 & 17.26 & 36.81 & 18.46 & 37.69 & 20.3 \\
\hline
\end{tabular}

For both men and women the level of life satisfaction increased from the year 2019 to the year 2020. In the case of men, this shift was statistically insignificant (Levene's test for equality of variances p-value $=0.616$, t-test with equal variances assumed p-value $=0.283)$ and in the case of women it was significant (Levene's test for equality of variances $p$-value $=0.129$, t-test with equal variances assumed p-value $=0.031)$. This result may seem rather curious, since it could be expected that the covid-19 pandemic would have a negative effect on people's happiness. Although the general trend of life satisfaction development is increasing in most 
countries (Helliwell et al., 2019) it seems unlikely that the shift between two years would be so pronounced. However, since this study is focused on studying the factors of life satisfaction and not on the total level of it, I do not elaborate on this matter any further.

As for the other variables, in the case of men the year-to-year change was also significant in the case of Alcohol (increase: Levene's test for equality of variances p-value $=0.001$, t-test with equal variances not assumed p-value $=0.019$ ) and TV (decrease: Levene's test for equality of variances p-value $=0.590$, t-test with equal variances assumed $\mathrm{p}$-value $=0.029)$. In the case of women, the year-to-year change was significant for variables Alcohol (increase, Levene's test for equality of variances $p$-value $=0.005$, t-test with equal variances not assumed p-value $=0.039$ ), Sport (increase: Levene's test for equality of variances p-value $=0.001$, t-test with equal variances not assumed p-value $=0.017$ ) and Transfers (increase: Levene's test for equality of variances $\mathrm{p}$-value $=0.001$, t-test with equal variances not assumed $\mathrm{p}$-value $=0.001)$.

\subsection{Regression Analysis}

Results introduced in this sub-section are based on logistic regression models. Table 3 presents regression outputs for men for both 2019 and 2020 while Table 4 does the same for women. I follow the usual statistical approach and take a variable as significant if the variable is significant on a $5 \%$ level of significance - p-value of the corresponding significance test is lower than 0.05 (two or three asterisks).

\begin{tabular}{|c|c|c|c|c|c|c|}
\hline & \multicolumn{3}{|c|}{2019} & \multicolumn{3}{|c|}{2020} \\
\hline Variable & Coeff & Std. Error & p-value & Coeff & Std. Error & p-value \\
\hline Physical Health & 0.478 & 0.084 & $<0.001 * * *$ & 0.255 & 0.075 & $0.00065^{* * * *}$ \\
\hline Mental Health & 0.544 & 0.083 & $<0.001$ **** & 0.521 & 0.079 & $<0.001 * * *$ \\
\hline Commuting Time & -0.001 & 0.003 & 0.845 & -0.002 & 0.003 & 0.466 \\
\hline Cigarettes & -0.002 & 0.019 & 0.901 & 0.015 & 0.020 & 0.456 \\
\hline Alcohol & 0.002 & 0.015 & 0.901 & -0.042 & 0.018 & $0.02125^{* *}$ \\
\hline Sport & 0.021 & 0.021 & 0.308 & -0.037 & 0.033 & 0.266 \\
\hline TV & -0.018 & 0.009 & $0.0543^{*}$ & -0.010 & 0.015 & 0.484 \\
\hline Friends & -0.004 & 0.011 & 0.732 & 0.010 & 0.009 & 0.270 \\
\hline Age & 0.007 & 0.016 & 0.673 & -0.002 & 0.018 & 0.889 \\
\hline Log Salary & 0.006 & 0.040 & 0.877 & -0.030 & 0.053 & 0.572 \\
\hline Log Transfers & 0.056 & 0.029 & $0.05188^{*}$ & -0.002 & 0.035 & 0.960 \\
\hline D Marital Status 2 & -0.010 & 0.293 & 0.974 & 1.553 & 0.324 & $<0.001 * * *$ \\
\hline D Marital Status 3 & 0.201 & 0.361 & 0.579 & 1.376 & 0.429 & 0.00135 **** \\
\hline D Education 2 & -0.146 & 0.397 & 0.714 & -0.478 & 0.510 & 0.348 \\
\hline D Education 3 & 0.205 & 0.357 & 0.565 & 0.164 & 0.436 & 0.706 \\
\hline D Education 4 & 0.760 & 0.517 & 0.141 & 1.056 & 0.601 & $0.0788^{*}$ \\
\hline D Education 5 & 0.149 & 0.529 & 0.779 & 0.562 & 0.667 & 0.400 \\
\hline D Work Status 2 & 0.079 & 0.397 & 0.842 & -0.829 & 0.449 & $0.06478^{*}$ \\
\hline D Work Status 3 & 0.363 & 0.770 & 0.637 & -1.063 & 0.776 & 0.170 \\
\hline D Work Status 4 & 0.490 & 0.860 & 0.569 & -0.163 & 0.993 & 0.869 \\
\hline Children Yes & -0.529 & 0.385 & 0.170 & 0.385 & 0.480 & 0.423 \\
\hline Model criteria & \multicolumn{3}{|c|}{ Cases correctly predicted $=38.0 \%$} & \multicolumn{3}{|c|}{ Cases correctly predicted $=39.9 \%$} \\
\hline
\end{tabular}

\subsection{Health}

In all four models (both men and women and both years 2019 and 2020) the variables concerning health (physical Health and mental Health) are significant with a positive coefficient. Clearly there is a strong relationship between health and happiness of the citizens of Usti nad Labem. As for the causality, its direction is not clear and cannot be determined using static data. There are many studies emphasizing the relationship between health (both physical or mental) and happiness (see, e.g., (Diener \& Chan, 2011; Lambert et al., 2014)). Since there is a large amount of evidence that health effects peoples' life satisfaction (see, e.g., Abedini and Majareh (2015)) I can conclude that as far as my sample is concerned, there is high probability that both physical and mental health of the subjects have positive effect on life satisfaction. Furthermore, the results show that this positive effect did not change with the coming of the Covid-19 pandemic in 2020. For both men and women, the coefficient belonging to mental health is greater than that belonging to physical health. This could signify the relatively higher importance of mental harmony in comparison to physical fitness.

For both men and women, the coefficients belonging to both physical health and mental health have a lower coefficient in the year 2020 when compared to the year 2019. The question arises whether the corresponding relationships (physical health and life satisfaction, mental health and life satisfaction) were significantly less strong in the year 2020 or whether these differences are only statistical interference. 
Table-4. Regression outputs, logistic regression, women.

\begin{tabular}{|c|c|c|c|c|c|c|}
\hline \multirow[b]{2}{*}{ Variable } & \multicolumn{3}{|c|}{2019} & \multicolumn{3}{|c|}{2020} \\
\hline & Coeff & Std. Error & p-value & Coeff & Std. Error & p-value \\
\hline Physical Health & 0.348 & 0.068 & $<0.001 * * *$ & 0.259 & 0.068 & $<0.001 * * *$ \\
\hline Mental Health & 0.529 & 0.069 & $<0.001 * * *$ & 0.439 & 0.064 & $<0.001 * * *$ \\
\hline Commuting Time & 0.002 & 0.003 & 0.478 & 0.006 & 0.003 & $0.06907^{*}$ \\
\hline Cigarettes & -0.048 & 0.020 & $0.01844 * *$ & -0.029 & 0.020 & 0.143 \\
\hline Alcohol & -0.019 & 0.027 & 0.467 & -0.067 & 0.020 & $0.00084^{* * * *}$ \\
\hline Sport & 0.005 & 0.028 & 0.861 & 0.049 & 0.020 & $0.01466^{* *}$ \\
\hline TV & -0.009 & 0.011 & 0.436 & 0.004 & 0.011 & 0.716 \\
\hline Friends & 0.001 & 0.010 & 0.898 & 0.013 & 0.010 & 0.183 \\
\hline Age & 0.018 & 0.015 & 0.214 & 0.008 & 0.016 & 0.614 \\
\hline Log Salary & -0.024 & 0.035 & 0.502 & -0.024 & 0.032 & 0.450 \\
\hline Log Transfers & 0.034 & 0.029 & 0.239 & -0.019 & 0.031 & 0.543 \\
\hline D Marital Status 2 & 0.183 & 0.260 & 0.481 & 0.637 & 0.268 & $0.0176^{* *}$ \\
\hline D Marital Status 3 & 0.563 & 0.314 & $0.07283^{*}$ & 0.711 & 0.308 & $0.02086^{* *}$ \\
\hline D Education 2 & -0.200 & 0.373 & 0.592 & -0.146 & 0.421 & 0.729 \\
\hline D Education 3 & -0.339 & 0.326 & 0.298 & 0.122 & 0.324 & 0.707 \\
\hline D Education 4 & -0.009 & 0.439 & 0.984 & 0.934 & 0.437 & $0.03251 * *$ \\
\hline D Education 5 & -0.349 & 0.473 & 0.461 & 0.806 & 0.595 & 0.176 \\
\hline D Work Status 2 & -0.024 & 0.414 & 0.954 & -0.291 & 0.437 & 0.505 \\
\hline D Work Status 3 & -0.573 & 0.596 & 0.337 & -0.606 & 0.736 & 0.411 \\
\hline D Work Status 4 & -0.781 & 0.711 & 0.272 & 0.644 & 0.806 & 0.424 \\
\hline Children Yes & -0.344 & 0.374 & 0.358 & -0.033 & 0.454 & 0.943 \\
\hline Model criteria & \multicolumn{3}{|c|}{ Cases correctly predicted $=36.7 \%$} & \multicolumn{3}{|c|}{ Cases correctly predicted $=35.5 \%$} \\
\hline
\end{tabular}

To determine whether each of these four differences is statistically significant, an analysis of betweensubjects effects was conducted for each of the aforementioned relationships. This method is based on the construction of a joint regression model for all subjects with the dependent variable life satisfaction and with all independent variables from the separate models plus a dummy variable for the year 2020 and an interacting variable of the factor multiplied by the variable year 2020 (e.g., physical health*Year 2020). If the interacting variable is significant, the test's outcome is that the difference between the two coefficients (here physical health in 2019 and physical health in the year 2020) is significant.

In the case of physical health of men, the interacting variable (here Physical_Health* Year_2020) is significant with p-value 0.040 with a negative coefficient, which means that for men in 2020 the relationship between their physical health and life satisfaction is weaker than in the year 2019. In the case of men and their mental health, the interacting variable is insignificant $(p$-value $=0.838)$ meaning that there is no statistically significant difference between men's mental health in 2019 and their mental health in 2020. In the case of women, the interacting variable is insignificant in both models (a model with interacting variable concerning physical health and a model with interacting variable concerning mental health - p-values 0.089 and 0.291). This means that for women, there is no significant difference between the importance of physical health in the year 2019 and its importance in the year 2020 while the same applies to their mental health.

\subsection{Smoking Cigarettes}

In the case of men, the variables belonging to physical and mental health are the only ones significant in the year 2019. As for women in the year 2019, there is also a significant negative relation between cigarettes and life satisfaction. The causality of this relationship can be also complex. Gajalakshmi, Peto, Kanaka, and Jha (2003) have described the negative effect of smoking on health. Peltzer and Pengpid (2013) have shown that tobacco use can have negative effect on life satisfaction. On the other hand, an opposite causality is possible: less happy people might have a higher inclination to smoke cigarettes (Conrad, Flay, \& Hill, 1992).

It is likely that in the year 2019 smoking had a negative effect on the life satisfaction of women. However, no relationship between these two variables has been found in the year 2020 for either men or women. It seems that the importance of smoking disappeared during the pandemic. The question arises whether it is possible that the role of tobacco use has been substituted by some other activity or substance. It is possible that the answer to this question might be provided by the regression results for the year 2020 (both men and women models) concerning the variable alcohol.

\subsection{Alcohol Consumption}

While in 2019 this variable was not found significant, in 2020 there is a negative relationship between drinking alcohol and life satisfaction for both men and women. The causal direction cannot be determined based on my data. There is a number of studies which show the harmful effect of alcohol both on health 
(Bewick et al., 2008) and on life satisfaction (Lambert et al., 2014). On the other hand, Kuntsche, Knibbe, Gmel, and Engels (2006) have shown that in difficult times people resort to drinking more often (opposite causality).

One possibility of the relationship appearing in 2020 is that in this year, alcohol started to affect the life satisfaction of people in the sample in a negative way. The opposite causal effect might apply as well: at the time of the pandemic, lower happiness started to be the cause of alcohol use. There is a number of studies showing that low life satisfaction can result in the higher consumption of alcohol in general (O'Connor \& Colder, 2005). However, the question would be why this effect did not apply before the pandemic. Although the social situation was undoubtedly different, one would still expect that with other factors fixed, less happy people tended to drink more alcohol. One possible explanation is that before the pandemic when someone felt bad, they had many options when it came to dealing with this situation: they could go to the cinema, they could visit their friends or they could go to a restaurant. During the pandemic, these possibilities were restricted by government restrictions. It is possible that as a result of this people dealt with their bad mood with alcohol more often. This would correspond to the fact that alcohol consumption during the pandemic in 2020 increased for both men and women.

\subsection{Sport}

In the case of women, the variable sport became significant in year 2020. The corresponding coefficient is positive indicating a positive relationship with life satisfaction. It seems improbable that with the pandemic a positive effect of happiness on sport participation would emerge. On the other hand, the positive effect of sport on well-being has been documented in many studies (see, e.g., (Biddle \& Asare, 2011; Suldo, Thalji-Raitano, Kiefer, \& Ferron, 2016)). If I assume that the "sport-happiness" causal effect applies, it is interesting as to why this effect did not appear before the pandemic. Similarly, as with alcohol consumption, it is possible that before the pandemic there were many ways of how to deal with stress or mental fatigue: visiting friends, attending cultural activities, etc. Although there could still be some positive effect of sport on happiness, it might have not been so significant. During the pandemic, on the other hand, these options were limited to those who were in compliance with the current government restrictions. Although many team sport activities were unavailable, there were still many ways in which one could exercise physically. Thus, it is likely that the role of sport became more important during the pandemic. As to why the significance of sport did not appear in the model for the year 2020 for men, it is possible that men unlike women deal with their bad moods not by doing more sport but by increasing their alcohol consumption.

\subsection{Partner Relationships and Marriage}

In 2019, in models for both men and women, the dummy variables related to marital status were not significant. In sharp comparison, in 2020, both marital status dummy variables were significant in models for both men and women with a positive coefficient. Firstly, here the "happiness-variable" causal direction would say that during the time of the pandemic happier people were more inclined to enter into a relationship or get married as opposed to the time before the pandemic where the relationship in question was not discovered. This is supported by the work of Mastekaasa (1992) and Frey (2008).

However, the average life satisfaction level did not decrease in 2020. Based on the hypothesis described above, it would be assumed that there would be more partnerships and marriages in 2020. As is illustrated in Figure 1, this did not happen. The number of single men without a partner remained almost the same (appx. $33 \%)$ and the number of married men decreased. The number of single women without a partner increased quite dramatically with the other two categories experiencing a decline. This means that there was not rise in the number of either partner relationship or marriages in the case of men nor in the case of women. Based on these results, the causal effect "happiness-marital status" seems improbable.

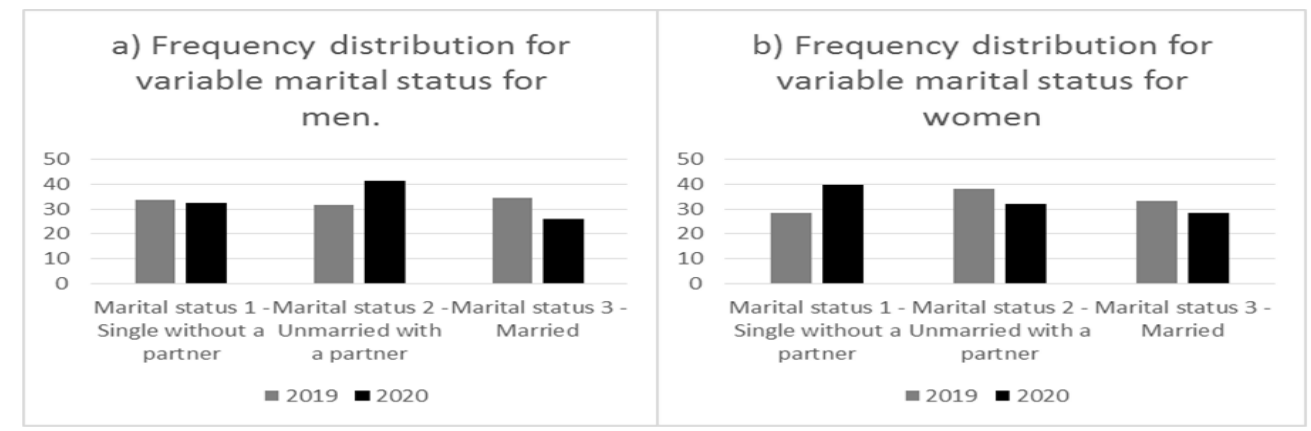

Figure-1. Frequency distribution for the variable marital status.

It is thus very likely that the causal direction "marital status - happiness" applies. Specifically, since all coefficients for all corresponding dummy variables are positive, being in a partner relationship or being 
married makes people happier. This is in line with many other studies (see, e.g., Marks and Lambert (1998)). In models for both men and women in the year 2020, the coefficient belonging to the dummy variable marital status 3 (married) is higher than the coefficient belonging to the dummy variable marital status 2 (unmarried with a partner). If the discussed causal direction applies, this means that being married brings more "happiness benefit" than being with a partner without being married.

However, this result does not necessarily mean that marriage makes people happier and that people should get married. Being married may simply be a proxy variable for having a good functional relationship as opposed to a relationship which has (possibly not yet) reached such level of maturity. In any case, results strongly indicate that the importance of partner relationships increased during the time of the pandemic. This general finding is in line with many other studies (see, e.g., (Diener et al., 2000; Frey, 2008)).

\subsection{Education}

Last variable which became significant in the year 2020 is D Education 4 - dummy variable standing for university bachelor's degree of education - in the case of women. The positive coefficient indicates that if the "education - happiness" causal direction applies, having achieved a bachelor's university degree has a positive effect on happiness. This variable is most likely correlated with other factors which can have positive effect on happiness - for example, being able to cope with difficulties and problems. On the other hand, the variable referring to university master's degree (D Education 5) was not found to be significant. This could point to the phenomenon called "overeducation" whose concept is that if people pursue more education than needed, the benefit can be very small or even negative (Bracke, Pattyn, \& Knesebeck, 2013).

\subsection{Research limitations}

The main limitation of this study is the nature of regression models - they do not show causal effects but relations only. Therefore, the interpretational potential of these results is limited. However, even under these circumstances, some conclusions can be made giving the outcomes practical value. In some cases, the causal direction can be approximated.

Another drawback of this analysis is the fact that the sample is not representative in relation to the population of the city in which the data was gathered. However, this imperfection does not take away the value of the results: the relations found in this study simply apply not to the whole population but to the population from which I took the sample.

It is of question to what extent can the results be generalized. It can be assumed that similar finding would apply in the case of different cities in the Czech Republic. International generalization should be tested by conducting a similar experiment elsewhere.

\section{Conclusion}

Results indicate large changes in the structure of factors of life satisfaction between the years 2019 and 2020. Except for physical and mental health the significance of all other factors which were significant in at least one of the models showed changes with the coming of the pandemic.

The results show that there are factors of happiness on which the Covid-19 pandemic had the same effect both in the case of men and in the case of women. These were: physical health, mental health, alcohol consumption and marital status. On the other hand, there are factors which became significant in the year 2020 only in the case of women: sport and education (namely university bachelor's degree). This implies that there are many behavioral patterns which are the same for both genders but some whose nature manifests differently as far as two genders are concerned. Thus, some implications and recommendations will apply to both men and women and some will be useful for one gender only.

For both men and women, interpersonal relationships became important. Being in a partner relationship has been found to be positively related with life satisfaction in 2020 when the pandemic was present. This association is even stronger for marriages. Although the causal direction cannot be determined with certainty, a likely scenario is that during this hard time, family ties and relations became a source of security and joy. The pandemic showed us the importance of partner relationships and families, which can easily be overlooked during "easy times". On the other hand, spending time with friends did not become a significant factor, possibly due to the fact that relationships inside a family bear more psychological importance.

While before the pandemic drinking alcohol did not bear any significance as far as factors of happiness are concerned, a negative relation with happiness appeared after the start of the pandemic. If alcohol consumption has negative effect on life satisfaction, it most likely applied both before the pandemic and during. Here, the emergence of this aspect as a significant factor can probably be attributed to the fact that during the pandemic people have less possibilities of dealing with stress and bad mood due to government restrictions on movement. Therefore, they resort to more accessible means of stress relief, such as alcohol consumption.

A similar behavioral pattern may have caused sport to become a significant positive factor of life satisfaction during the pandemic for women. With fewer attainable ways of keeping their mind in balance, women probably started to take full advantage of sport activities. The results clearly show that factors of life satisfaction are sensitive to changes in social and health conditions. Family relationships become important 
and people resort to accessible means of gratification and dealing with stress (here alcohol and sport). Whether this type of behavior is suitable and effective is impossible to determine but giving people information about these phenomena, which they might not be aware of, can provide space for conscious choosing of what way of dealing with the current situation is appropriate for oneself. For instance, it seems that partner relationships and doing sports can be good substitutes for alcohol consumption. This exchange can be especially profitable knowing that while there is a positive relationship between family relationships and happiness and between sport time and happiness, the relationship between alcohol consumption and life satisfaction is negative. Thus, making personal relationships and engaging in sport activities better ways of dealing with difficult times. Furthermore, it is possible that results similar to those of this study will be found when investigating the effect of some other social or economic change. Thus, results of this study could to some extent predict the change of factors of life satisfaction when some other difficult social change comes. However, being only a hypothesis this should be investigated more - it is also possible that other social change will have a different effect on factors of life satisfaction. Since results of this study are based on a sample of people of one city, it is advisable that such research be replicated among different social backgrounds. It is possible that in different cultural, and different social and economic environment the outcomes of such research would be different. Factors which have become the source of security and joy during hard times in one culture may be different from important life satisfaction factors of a different culture or country.

\section{References}

Abedini, M., \& Majareh, S. A. (2015). Study of relationships among lifestyle, health locus of control, and happiness in students. Basic \& Clinical Cancer Research, 7(4), 9-17.

Ashraf, B. N. (2020). Economic impact of government interventions during the COVID-19 pandemic: International evidence from financial markets. Journal of Behavioral and Experimental Finance, 27, 100371. Available at: https://doi.org/10.1016/j.jbef.2020.100371.

Benyamini, Y., Idler, E. L., Leventhal, H., \& Leventhal, E. A. (2000). Positive affect and function as influences on selfassessments of health: Expanding our view beyond illness and disability. The Journals of Gerontology Series B: Psychological Sciences and Social Sciences, 55(2), P107-P116. Available at: https://doi.org/10.1093/geronb/55.2.P107.

Bewick, B. M., Mulhern, B., Barkham, M., Trusler, K., Hill, A. J., \& Stiles, W. B. (2008). Changes in undergraduate student alcohol consumption as they progress through university. BMC Public Health, 8(1), 163. Available at: https://doi.org/10.1186/1471-2458-8-163.

Biddle, S. J. H., \& Asare, M. (2011). Physical activity and mental health in children and adolescents: A review of reviews. British Journal of Sports Medicine, 45(1), 886-895. Available at: https://doi.org/10.1136/bjsports-2011-090185.

Bitler, M., Hoynes, H. W., \& Schanzenbach, D. W. (2020). The social safety net in the wake of COVID-19 (No. w27796). National Bureau of Economic Research.

Bracke, P., Pattyn, E., \& Knesebeck, V. D. O. (2013). Overeducation and depressive symptoms: Diminishing mental health returns to education. Sociology of Health \& Illness, 35(8), 1242-1259. Available at: https://doi.org/10.1111/14679566.12039.

Conrad, K. M., Flay, B. R., \& Hill, D. (1992). Why children start smoking cigarettes: Predictors of onset. British Journal of Addiction, 87(12), 1711-1724. Available at: https://doi.org/10.1111/j.1360-0443.1992.tbo2684.x.

D’Agostino, A., Gagliardi, F., Giusti, C., \& Potsi, A. (2019). Investigating the impact of the economic crisis on children's wellbeing in four European countries. Social Science Research, 84, 102322. Available at: https://doi.org/10.1016/j.ssresearch.2019.06.013.

De Souza, L. E. C., De Lima, T. J. S., Ribeiro, E. M., Pessoa, A. L. S., Figueiredo, T. C., \& Lima, L. B. P. (2018). Mental health of parents of children with congenital Zika virus syndrome in Brazil. Journal of Child and Family Studies, 27(4), 1207-1215. Available at: https://doi.org/10.1007/s 10826-017-0969-0.

Diener, E., \& Chan, M. Y. (2011). Happy people live longer: Subjective well-being contributes to health and longevity. Applied Psychology: Health and Well-Being, 3(1), 1-43. Available at: https://doi.org/10.1111/j.17580854.2010.01045.x.

Diener, E., Gohm, C. 1., Suh, E., \& Oishi, S. (2000). Similarity of the relations between marital status and subjective wellbeing across cultures. Journal of Cross-Cultural Psychology, 31(4), 419-436. Available at: https://doi.org/10.1177/0022022100031004001.

Fezzi, C., \& Fanghella, V. (2020). Real-time estimation of the short-run impact of COVID-19 on economic activity using electricity market data. Environmental and Resource Economics, 76(4), 885-900. Available at: https://doi.org/10.1007/s10640-020-00467-4.

Frey, B. S. (2008). Happiness: A revolution in economics. Cambridge Massachusetts: The MIT Press.

Gajalakshmi, V., Peto, R., Kanaka, T. S., \& Jha, P. (2003). Smoking and mortality from tuberculosis and other diseases in India: Retrospective study of 43000 adult male deaths and 35000 controls. The Lancet, 362(9383), 507-515. Available at: https://doi.org/10.1016/So 140-6736(03)14109-8.

Garfin, D. R., Silver, R. C., \& Holman, E. A. (2020). The novel coronavirus (COVID-2019) outbreak: Amplification of public health consequences by media exposure. Health Psychology: Official Journal of the Division of Health Psychology, American Psychological Association, 39(5), 355-357. Available at: https://doi.org/10.1037/hea0000875.

Gonza, G., \& Burger, A. (2017). Subjective well-being during the 2008 economic crisis: Identification of mediating and moderating factors. Journal of Happiness Studies, 18(6), 1763-1797. Available at: https://doi.org/10.1007/s 10902016-9797-y. 
Hassan, G., Ventevogel, P., Jefee-Bahloul, H., Barkil-Oteo, A., \& Kirmayer, L. J. (2016). Mental health and psychosocial wellbeing of Syrians affected by armed conflict. Epidemiology and Psychiatric Sciences, 25(2), 129-141. Available at: https://doi.org/10.1017/S2045796016000044.

Helliwell, J., Layard, R., \& Sachs, J. (2019). World happiness report 2019. New York: Sustainable Development Solutions Network.

Iacus, S. M., Natale, F., Santamaria, C., Spyratos, S., \& Vespe, M. (2020). Estimating and projecting air passenger traffic during the COVID-19 coronavirus outbreak and its socio-economic impact. Safety Science, 129, 104791. Available at: https://doi.org/10.1016/j.ssci.2020.104791.

Janáček, J., \& Rybáček, V. (2020). Commuting time and life satisfaction of high school students in the Czech Republic, Italy and Slovenia. Prague Economic Papers, 29(5), 561-574.

Kahneman, D., \& Deaton, A. (2010). High income improves evaluation of life but not emotional well-being. Proceedings of the National Academy of Sciences of the United States of America, 107(38), 16489-16493. Available at: https://doi.org/10.1073/pnas.1011492107.

Kivi, M., Hansson, I., \& Bjälkebring, P. (2021). Up and about: Older adults' well-being during the COVID-19 pandemic in a Swedish longitudinal study. The Journals of Gerontology: Series B, 76(2), e4-e9. Available at: https://doi.org/10.1093/geronb/gbaa084.

Kulkarni, V. S. (2015). Correlates of self-rated health status in the context of Sri Lanka. The Journal of Developing Areas, 49(4), 145-165. Available at: https://doi.org/10.1353/jda.2015.0130.

Kuntsche, E., Knibbe, R., Gmel, G., \& Engels, R. (2006). Who drinks and why? A review of socio-demographic, personality, and contextual issues behind the drinking motives in young people. Addictive Behaviors, 31(10), 1844-1857. Available at: https://doi.org/10.1016/j.addbeh.2005.12.028.

Lambert, M., Fleming, T., Ameratunga, S., Robinson, E., Crengle, S., Sheridan, J., \& Merry, S. (2014). Looking on the bright side: An assessment of factors associated with adolescents' happiness. Advances in Mental Health, 12(2), 101-109. Available at: https://doi.org/10.1080/18374905.2014.11081888.

Marks, N. F., \& Lambert, J. D. (1998). Marital status continuity and change among young and midlife adults: Longitudinal effects on psychological well-being. Journal of Family Issues, 19(6), 652-686. Available at: https://doi.org/10.1177/019251398019006001.

Mastekaasa, A. (1992). Marriage and psychological well-being: Some evidence on selection into marriage. Journal of Marriage and Family, 54(4), 901-911. Available at: https://doi.org/10.2307/353171.

Mulligan, C. B. (2021). Economic activity and the value of medical innovation during a pandemic. Journal of Benefit-Cost Analysis, 12(3), 420-440.

O'Connor, R. M., \& Colder, C. R. (2005). Predicting alcohol patterns in first-year college students through motivational systems and reasons for drinking. Psychology of Addictive Behaviors, 19(1), 10-20. Available at: https://doi.org/10.1037/0893-164X.19.1.10.

Pak, A., Adegboye, O. A., Adekunle, A. I., Rahman, K. M., McBryde, E. S., \& Eisen, D. P. (2020). Economic consequences of the COVID-19 outbreak: The need for epidemic preparedness. Frontiers in Public Health, 8, 241. Available at: https://doi.org/10.3389/fpubh.2020.00241.

Patrick, S. W., Henkhaus, L. E., Zickafoose, J. S., Lovell, K., Halvorson, A., Loch, S., \& Davis, M. M. (2020). Well-being of parents and children during the COVID-19 pandemic: A national survey. Pediatrics, 146(4), e2020016824. Available at: https://doi.org/10.1542/peds.2020-016824.

Peltzer, K., \& Pengpid, S. (2013). Subjective happiness and health behavior among a sample of university students in India. Social Behavior \& Personality: An International Journal, 41(6), 1045-1056. Available at: https://doi.org/10.2224/sbp.2013.41.6.1045.

Qiu, R. T. R., Park, J., Li, S., \& Song, H. (2020). Social costs of tourism during the COVID-19 pandemic. Annals of Tourism Research, 84, 102994. Available at: https://doi.org/10.1016/j.annals.2020.102994.

Ren, Q., \& Treiman, D. J. (2016). The consequences of parental labor migration in China for children's emotional wellbeing. Social Science Research, 58, 46-67. Available at: https://doi.org/10.1016/j.ssresearch.2016.03.003.

Sarracino, F., \& Piekałkiewicz, M. (2021). The role of income and social capital for Europeans' well-being during the 2008 economic crisis. Journal of Happiness Studies, 22(4), 1583-1610. Available at: https://doi.org/10.1007/s 10902020-00285-x.

Suldo, S. M., Thalji-Raitano, A., Kiefer, S. M., \& Ferron, J. M. (2016). Conceptualizing high school students' mental health through a dual-factor model. School Psychology Review, 45(4), 434-457. Available at: https://doi.org/10.17105/SPR45-4.434-457.

Teerawichitchainan, B., \& Korinek, K. (2012). The long-term impact of war on health and wellbeing in Northern Vietnam: Some glimpses from a recent survey. Social Science \& Medicine, 74(12), 1995-2004. Available at: https://doi.org/10.1016/j.socscimed.2012.01.040.

Wanberg, C., Csillag, B., Douglass, R., Zhou, L., \& Pollard, M. (2020). Socioeconomic status and well-being during COVID-19: A resource-based examination. The Journal of Applied Psychology, 105(12), 1382-1396. Available at: https://doi.org/10.1037/aplooo0831.

Yadav, S., \& Rawal, G. (2015). The current mental health status of Ebola survivors in Western Africa. Journal of Clinical and Diagnostic Research: JCDR, 9(10), LA01-LA02. Available at: https://doi.org/10.7860/JCDR/2015/15127.6559.

Zacher, H., \& Rudolph, C. W. (2021). Individual differences and changes in subjective wellbeing during the early stages of the COVID-19 pandemic. American Psychologist, 76(1), 50-62. Available at: https://doi.org/10.1037/amp0000702. 